\title{
Stress Distribution in Porcelain-Fused-to-Gold Crowns and Preparations Constructed with Photoelastic Plastics
}

\author{
R. G. CRAIG, M. K. EL-EBRASHI, and F. A. PEYTON \\ School of Dentistry, University of Michigan, Ann Arbor, Michigan 48104, USA
}

Composite models representing porcelainfused-to-gold restorations were constructed from photoelastic plastics. Better stress distributions resulted when the porcelain-gold joint was as far as feasible from the loading site, a bulk of gold was present on the lingual shoulder, and the porcelain-gold joint at the shoulder was $30^{\circ}$ from the horizontal.

Extensive restorations of single anterior teeth are accomplished by using porcelain jacket crowns or porcelain enamel or plastic veneer restorations supported by an alloy restoration that is luted to the tooth. The porcelain jacket crown has the advantage that less tooth tissue must be removed, but the material is brittle and lacks impact strength. Studies by McLean ${ }^{1,2}$ have shown that these restorations can be improved considerably by the use of alumina-reinforced porcelain and he estimates an $80 \%$ improvement in the flexural strength of these materials.

Porcelain-fused-to-metal restorations increased in popularity as a result of the development of low-fusing porcelain enamels with coefficients of thermal expansion similar to those of the supporting metal. The development of higher melting gold alloys that did not decrease in hardness with repeated firing also was an important advance, ${ }^{3}$

The bond strength developed between porcelain enamels and gold alloys has received considerable attention, ${ }^{4-6}$ and although there is some question regarding whether it is a van der Waals bond or a

This investigation was supported by USPHS Research Grant DE-01817 from the National Institute for Dental Research, National Institutes of Health, Bethesda, Md. Presented at the 46th General Meeting of the IADR, San Francisco, Calif, March 1968.

Received for publication June 4, 1970. chemical bond, it has been established that smooth bonding surfaces are better and the tensile strength of the porcelain enamel is less than that of the bond. The mechanical properties of dental porcelain have been presented by Nally and Berta. ${ }^{7}$

A number of articles $^{8-11}$ have been published on the clinical aspects of porcelain enamel-fused-to-metal restorations. Laboratory studies of jacket crowns were reported by Conod, ${ }^{12}$ Rumetsch, Schreiber, and Motsch, ${ }^{13}$ and Walton and Leven. ${ }^{14}$ The first two studies dealt with the statics of jacket crowns; the former was a theoretical discussion and the latter included two dimensional photoelastic measurements of jacket restorations that had different shoulder geometries. The study by Walton and Leven ${ }^{14}$ was a three dimensional photoelastic investigation; they studied slices from jacket models near the incisal edge and parallel with the labial surface; parallel to the incisal edge and a third to a half the distance from the incisal edge to the gingival surface; and following the gingival contour.

Stress analysis of porcelain enamel-fusedto-metal restorations has not been reported; it was the purpose of this study to examine the stress distribution in these restorations and the supporting structure by use of different designs, loading sites, and magnitudes of load. A two dimensional photoelastic technique was used with different plastics representing the various materials; labial-lingual and mesial-distal sections were examined for the state of stress.

\section{Materials and Methods}

Three photoelastic plastics were used: (1) PSM-1* with an elastic modulus of 340,000 pounds $/$ in $^{2}$ and a fringe constant

* Photolastic, Inc., Malvern, Pa. 
of 40 pounds/ $\mathrm{in}^{2} /$ fringe/in; (2) PSM-5* with an elastic modulus of 450,000 pounds/ in $^{2}$ and a fringe constant of 60 pounds/in ${ }^{2} /$ fringe/in; and (3) PL-2* with an elastic modulus of 100,000 pounds/in ${ }^{2}$ and a fringe constant of 37.8 pounds/ $\mathrm{in}^{2} /$ fringe/ in.

The PSM-1 represented the porcelain enamel, the PSM-5 the gold alloy, and the PL-2 the dentin. The ratios of $3.4: 4.5: 1$ for the elastic moduli of the plastics were comparable to those of the restorative materials and dentin 3.6:5.0:1.

In the construction of the models, the peripheral outline of the restorations and the dentin were kept constant and the geometry of the gold and porcelain enamel sections was varied. The appropriate sections were cut from a quarter inch sheet of plastic and the porcelain enamel and gold sections were cemented together with an epoxy cement that had a modulus similar to the porcelain section. The cemented restoration was luted to the plastic representing the dentin by use of dental stone. A lower modulus material similar to PL-2 would improve the model further, but it was believed the stone did not invalidate the model even though the modulus was higher than desired.

The models were eight times the normal size of a maxillary central incisor and were placed in a standard circular polariscope and loaded at the desired position and load. The interference patterns were recorded photographically. The mesial-distal sections were loaded over the center of the pulpal floor and over the intersection of the pulpal floor and the axial wall. Loads of 30,60 , and 90 pounds were used at these two sites. The labial-lingual sections were loaded on the incisal edge and the cingulum with loads of 15,30 , and 45 pounds. The lingual surface was accentuated to allow vertical loading in this region. In addition, a few models were loaded a third of the distance from the incisal edge to the cingulum by applying a bending moment to the model.

The six different labial-lingual and five different mesial-distal models are shown in Figures 1 and 2, respectively. The geometry of the gold shoulder was based on previous studies $^{15}$ where a shoulder with rounded angles was found to be superior. The geometry of the gold-porcelain enamel

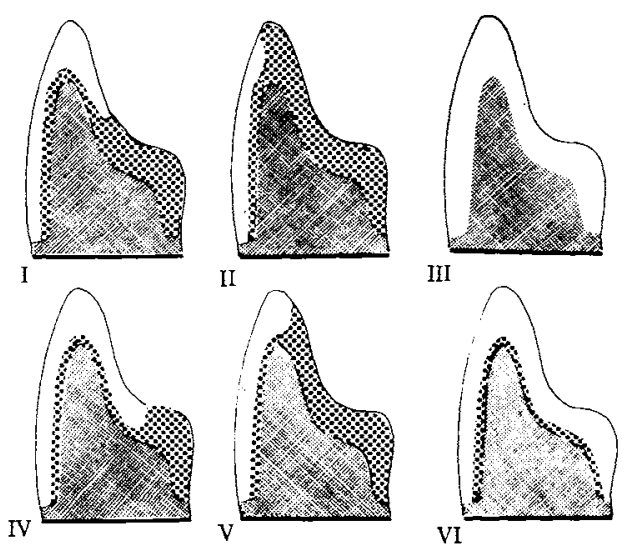

FIG 1.-Geometry of six labial-lingual sections; white represents porcelain, checks represent gold, and criss-cross represents dentin.

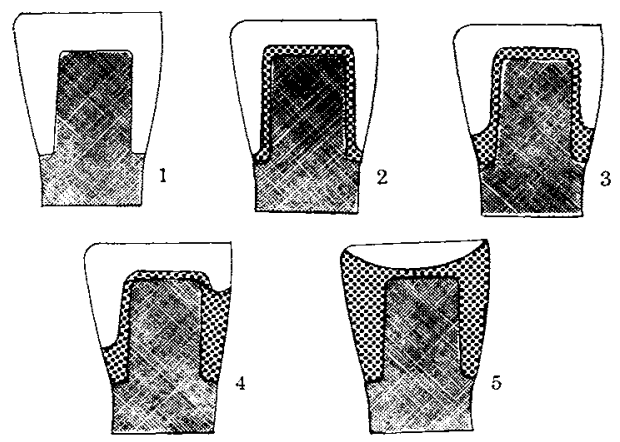

FIG 2.-Geometry of five mesial-distal sections; white represents porcelain, checks represent gold, and criss-cross represents dentin.

shoulder was determined using simplified models constructed of the plastics described previously. A butt joint, a sloping shoulder $\left(30^{\circ}\right.$ to the horizontal), and another sloping shoulder $\left(45^{\circ}\right.$ to the horizontal) were studied photoelastically. The sloping shoulder of $30^{\circ}$ had the lowest stress concentration factor and therefore was used in all restorations in this study.

\section{Results}

Selected photoelastic stress patterns will be presented here but a more complete series may be observed. ${ }^{16}$ Labial-lingual models loaded at 45 pounds were chosen and models I and II, loaded on the incisal edge, are shown in Figure 3. Areas $A, B$, and $C$ were selected to estimate the state 


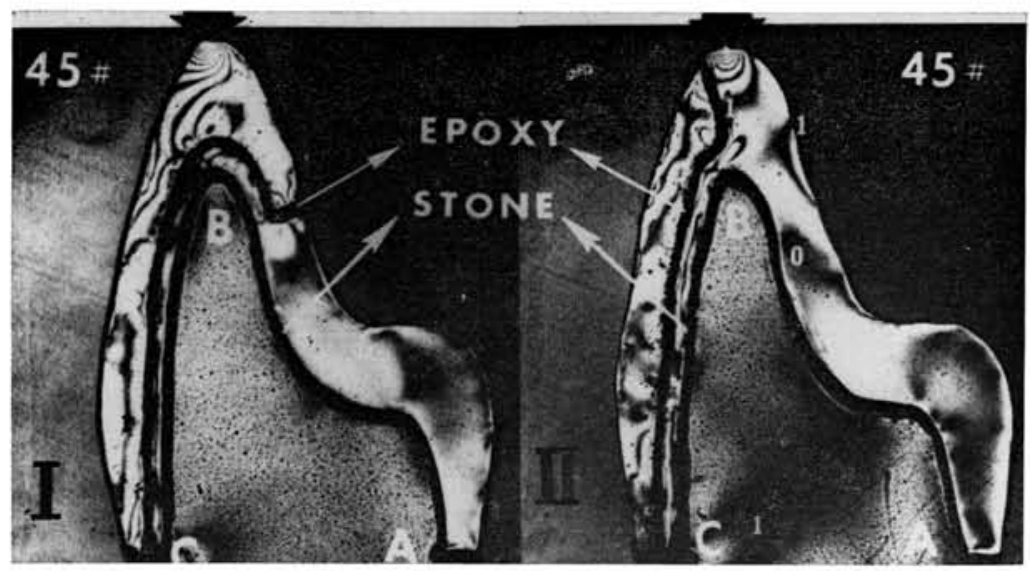

FIG 3.-Labial-lingual models I and II loaded incisally with 45 pounds. $A-C$, areas selected to estimate state of stress; $0-1$, fringe orders.

of stress in the portion of the model representing dentin. A few of the fringes are labeled with their order to give an indication of the shear stress. Photoelastic stress patterns for other labial-lingual models loaded in the same manner showed that considerably higher fringe orders occurred on the lingual portions of models III and IV than in the other four models, and the stress was tensile in this region. Low fringe orders were found in the plastic representing dentin in all instances. When models $\mathrm{I}$ and VI were loaded with 45 pounds in the region of the cingulum, higher fringe orders were observed in model VI (complete porcelain coverage of gold) for comparable regions, than in model I where gold covered the cingulum and half of the lingual surface.

The model representing the porcelain jacket crown is shown in Figure 4. When it was loaded on the lingual surface at a bending moment of 11 pounds-in, the restoration did not fail but high tensile stress concentrations were observed in the lingual shoulder region and high compressive stresses were seen in the labial shoulder region. The application of a moment of 13 pounds-in resulted in tensile rupture of the luted model at the gingival region on the lingual aspect. When rupture occurred, the state of stress of the substructure increased considerably.

Analysis of variance was determined using a grid method ${ }^{15}$ and it was found that the designs were different at the $P<0.005$ level of significance. As expected, the magnitude of the loads were different but the sites were not significantly different. One first order interaction was significant-that between the site and the magnitude of load.

The effect of the design on the state of stress in the dentin region is indicated in Table 1 for labial-lingual models I to VI, using sites $A, B$, and $C$ and incisal and lingual loading. The number indicates the absolute fringe order. The mean fringe order indicates the state of stress in the dentin region. Model II, with incisal gold protection, had the lowest value (0.58) followed by I, IV, V, VI, and III. Thus, the porcelain jacket crown transferred the most stress to the supporting tooth structure. Model II, with incisal gold, provided low transfer of stress to the substructure.

The mesial-distal sections selected to be shown were loaded at 60 pounds. The photoelastic stress pattern of model 1 , the full porcelain jacket, is shown in Figure 5 loaded laterally and centrally. The mesialdistal section of model 4 was not symmetrical and thus two lateral loadings were made. Lower fringes were observed in comparable regions in the porcelain when the loading was on the side with more porcelain. This is true because of the larger size of the restoration on the right (the section was not symmetrical). Model 5 had minimal stress in the gold region because of the large mass of gold.

Analysis of variance showed that the models were different at $P<0.005$. The 
TABLE 1

Mean Absolute Fringe Order $(\bar{x})$ for Sites $A, B$, and $C$ OF MODELS I TO VI

\begin{tabular}{|c|c|c|c|c|c|c|c|}
\hline \multirow[b]{2}{*}{ Model } & \multicolumn{2}{|c|}{$A$} & \multicolumn{2}{|c|}{$B$} & \multicolumn{2}{|c|}{$C$} & \multirow[b]{2}{*}{$\bar{x}$} \\
\hline & $I^{*}$ & $\boldsymbol{L}_{\dagger}$ & $I$ & $L$ & $I$ & $L$ & \\
\hline I & 0 & 1 & 0 & 0 & 3.0 & 0 & 0.67 \\
\hline II & 0 & 1 & 0 & 0 & 1.5 & 1 & 0.58 \\
\hline III & 3 & 3 & 0 & 0 & 3.0 & 0 & 1.5 \\
\hline IV & 1 & 2 & 0 & 1 & 2.0 & 0 & 1.0 \\
\hline V & 0 & 2 & 0 & 1 & 3.0 & 1 & 1.16 \\
\hline VI & 1 & 3 & 0 & 0 & 3.0 & 0 & 1.16 \\
\hline
\end{tabular}

magnitudes of the load were significant and the site of the load was not significant. A summary of the fringe orders at sites $A, B$, $C$, and $D$ is given in Table 2. Mesial-distal model 3, which had a sizable bulk of gold at the gingival site, had the lowest mean fringe value $(0.87)$ followed by $4,2,5$, and 1. The highest state of stress was again indicated for the porcelain jacket crown (1.69).

\section{Discussion}

The results of the studies by Rumetsch, Schreiber, and Motsch ${ }^{13}$ are not in agreement with previous and present studies by the authors. Rumetsch, Schreiber, and Motsch $^{13}$ reported lower fringe orders in mesial-distal sections of jacket crowns near the margin when a chisel shoulder was used, and twice as many fringes were observed when a rounded shoulder was substituted. The models were supported on metal bases and, if they were not luted to the base with stone or cement, large variations would occur as a result of nonuniform contact of the restoration with the base. The differences in seating can overshadow any variation in geometry of the restoration. Walton and Leven's ${ }^{14}$ findings generally agreed with those of the present investigation and suggested a thick labial section with a square or acute shoulder to support the compressive stress. The lingual shoulder was found to have little relation to the load on the incisal edge of the maxillary teeth, but maximum mesial-distal width of the preparation was important.

The results of the present study indicate

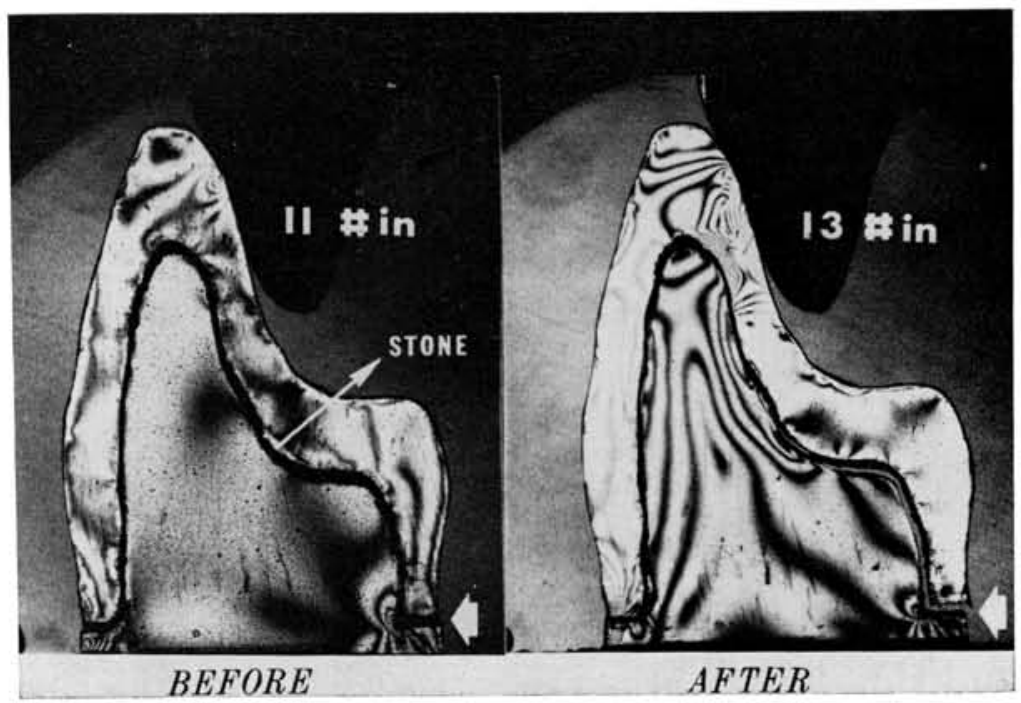

FIG 4.-Labial-lingual model III loaded to give 11 and $13 \mathrm{in} /$ pound of moment. Fracture of stone joint occurred just before 13 in/pound moment. 
TABLE 2

Mean Absolute Fringe Order $(\bar{x})$ for Sites $A, B, C$, AND $D$ OF MODELS 1 TO 5

\begin{tabular}{|c|c|c|c|c|c|c|c|c|c|}
\hline \multirow[b]{2}{*}{ Model } & \multicolumn{2}{|c|}{$A$} & \multicolumn{2}{|c|}{$B$} & \multicolumn{2}{|c|}{$C$} & \multicolumn{2}{|c|}{$D$} & \multirow[b]{2}{*}{$\tilde{x}$} \\
\hline & $L^{*}$ & $C \dagger$ & $L$ & $C$ & $L$ & $C$ & $L$ & $C$ & \\
\hline 1 & 1 & 0.5 & 0.0 & 0.0 & 5 & 3 & 3 & 1.0 & 1.69 \\
\hline 2 & 2 & 0.0 & 0.5 & 0.5 & 3 & 2 & 2 & 0.5 & 1.31 \\
\hline 3 & 1 & 0.0 & 1.0 & 1.0 & 0 & 0 & 3 & 1.0 & 0.87 \\
\hline 4 & 2 & 0.0 & 1.0 & 0.0 & 2 & 0 & 3 & 0.5 & 1.06 \\
\hline 5 & 2 & 0.5 & 1.0 & 0.0 & 3 & 1 & 3 & 1.0 & 1.43 \\
\hline
\end{tabular}

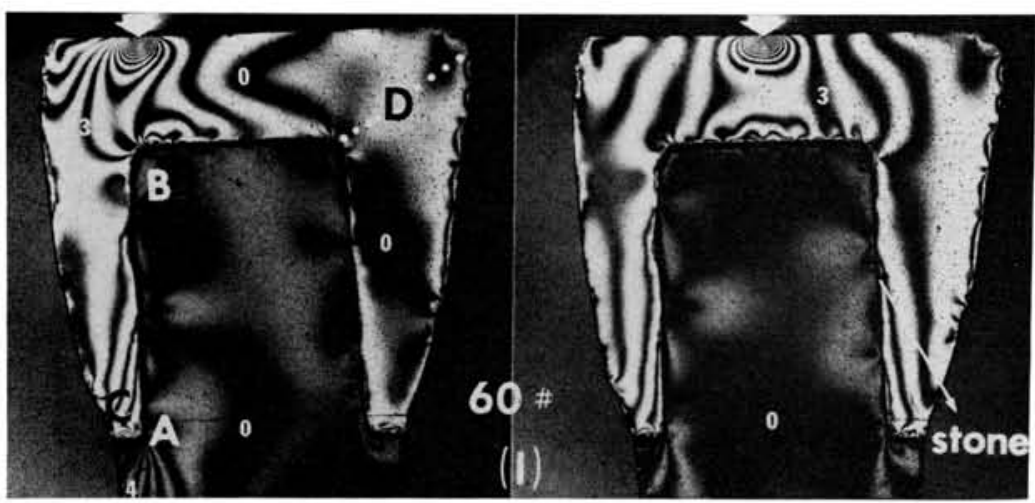

FIg 5.-Mesial-distal model 1 loaded laterally and centrally with 60 pounds. $A-D$, areas selected to estimate state of stress; $0-3$, fringe orders.

that restorations with a gold support were superior to porcelain enamel jacket crowns, and that providing increased bulk of gold in the gingival region reduced the state of stress in the combination of restoration and supporting structure.

The data also indicate that the goldporcelain joint should not be near the site of load application on the lingual shoulder if the state of stress is to be minimized. This effect was indicated in the lingual loading of the restorations having joints on the lingual shoulder near the incisal region and in the flat region of the accentuated cingulum. A thin gold shell completely covered with porcelain resulted in higher states of stress when loaded than when a larger bulk of gold was allowed on the lingual and labial sides. This suggestion, of course, must be reconciled with esthetics.

The question of whether the stress distribution in a two dimensional model is a reliable indication of the stress distribution in a three dimensional model is important. A study by Farah and Craig ${ }^{17}$ using photo- elastic coatings on an actual gold bridge showed the same distribution of stress as a two dimensional photoelastic study of the bridge by El-Ebrashi, Craig, and Peyton, ${ }^{18}$ which supports the validity of two dimensional studies.

\section{Conclusions}

The effect of the geometry of porcelainfused-to-gold restorations on the stress distribution during loading was studied using a two dimensional photoelastic technique. Composite models were constructed with three photoelastic plastics that had nearly the same ratio of elastic moduli as porcelain, gold, and dentin. Various labiallingual and mesial-distal models were constructed and loaded under a variety of conditions. The state of stress was evaluated using related sites in the restoration and the substructure. Analysis of variance showed the designs were significantly different and that the loads were different, but the sites of load were not. The first order interaction between load and site was significant. Based 
on the state of stress, it was found that (1) the gold-porcelain joint near the shoulder should be $30^{\circ}$ from the horizontal; (2) porcelain supported by gold was superior to a porcelain-enamel jacket crown; (3) a bulk of gold in the gingival region reduces the state of stress; (4) the porcelain-gold joint on the lingual shoulder should be as far as feasible from the site of loading; and (5) complete porcelain coverage of metal is not superior to providing a bulk of gold on the lingual shoulder.

\section{References}

1. McLean, J.W., and Hughes, T.H.: The Reinforcement of Dental Porcelain with Ceramic Oxides, Brit Dent J 119:251-272, 1965.

2. McLean, J.W.: The Alumina Reinforced Porcelain Jacket Crown, JADA 75:621$628,1967$.

3. O'Brien, W.J.; Kring, J.E.; and Ryge, G.: Heat Treatment of Alloys to be Used for the Fused Porcelain Technique, $J$ Prosth Dent 14:955-960, 1964.

4. Shell, J.S., and Nielsen, J.P.: Study of the Bond between Gold Alloys and Porcelain, J Dent Res 41:1424-1437, 1962.

5. Ryge, G.: Current American Research on Porcelain-Fused-to-Metal Restorations, Int Dent J 15:385-392, 1965.

6. KNap, F.J., and RYGe, G.: Study of Bond Strength of Dental Porcelain Fused to Metal, J Dent Res 45:1047-1051, 1966.

7. NALLY, J.N., and BERTA, J.J.: Recherches Experimentales sur les Proprietes Mecaniques des Ceramiques Cuites sur Alliages, Schweiz Mschr Zahnheilk 75:93-104, 1965.

8. Masterton, J.B., and Davis, V.M.: Complete Veneer Gold-Porcelain Bonded Crowns, An Evaluation of Aesthetics, Design, and Applications in the Light of
Clinical Experience, Dent Pract 14:449$463,1964$.

9. Mumford, G.: The Porcelain Fused to Metal Restoration, Dent Clin $N$ Amer March 1965, pp 241-249.

10. Straussberg, G.; Katz, G.; and Kuwata, M.: Design of Gold Supporting Structures for Fused Porcelain Restorations, J Prosth Dent 16:928-936, 1966.

11. Ney-oro Gold-porcelain Technic, Hartford, Conn: The J.M. Ney Company.

12. ConOD, H.: Etude sur la Statique de la Couronne Jaquette, Schweiz Mtschr Zahnheilk 47:483-529, 1937.

13. Rumetsch, W.; Schreiber, S.; and Motsch, A.: Zur Statik der Jaktkrone: Sponnungsoptische Modellversuch, Schweiz Mtschr Zahnheilk 75:953-975, 1965.

14. Walton, C.B., and Leven, M.M.: A Preliminary Report of Photoelastic Tests of Strain Patterns Within Jacket Crowns, JADA 50:44-48, 1955 .

15. El-Ebrashi, M.K.; Craig, R.G.; and PeyTON, F.A.: Experimental Stress Analysis of Dental Restorations, Part III. The Concept of the Geometry of Proximal Martins, J Prosth Dent 22:333-345, 1969.

16. Craig, R.G.; El-Ebrashi, M.K.; and PeYTON, F.A.: Stress Distribution in Porcelain Fused to Gold Alloy Crowns and Preparations Using Photoelasticity, Microfilm Dental Materials Group Papers, IADR, 46th General Meeting, San Francisco, Calif, March 1968.

17. Farah, J.W., and Craig, R.G.: Reflection Photoelastic Stress Analysis of a Dental Bridge, J Dent Res 50:1253-1259, 1971.

18. El-Ebrashi, M.K.; Craig, R.G.; and PeyTON, F.A.: Experimental Stress Analysis of Dental Restorations, Part VII. Structural Design and Stress Analysis of Fixed Partial Dentures, $J$ Prosth Dent 23:177$186,1970$. 